This work is licensed under a Creative Commons Attribution License (CC BY 4.0).

Research article

urn:1sid:zoobank.org:pub:0D71B8D0-EC39-42EC-9052-D2F99B47EE0B

\title{
The genus Alexeter Förster (Hymenoptera, Ichneumonidae) in China, with descriptions of three new species
}

\author{
Tao LI ${ }^{1, *} \&$ Shu-Ping SUN (1) ${ }^{2}$ \\ ${ }^{1,2}$ General Station of Forest and Grassland Pest Management, \\ National Forestry and Grassland Administration, \\ 58 Huanghe North Street, Shenyang 110034, P.R. China. \\ ${ }^{*}$ Corresponding author: litao200105@163.com \\ 2Email: sfzzssp@163.com \\ ${ }^{1}$ urn:1sid:zoobank.org:author:AE2C4D7F-6132-4A33-A5EC-04CF541BD80E \\ ${ }^{2}$ urn:1sid:zoobank.org:author:974C0354-6118-4EA9-890F-EF5ECE8F257A
}

\begin{abstract}
Three new species of Alexeter Förster, 1869 are reported from China, A. flavicoxa Li \& Sun sp. nov. collected from Sichuan, A. flaviventris Li \& Sun sp. nov. from Beijing, Guizhou and A. melanicus Li \& Sun sp. nov. from Guizhou. A key to species of Alexeter known in China is provided.
\end{abstract}

Keywords. Alexeter, Ctenopelmatinae, key, Mesoleiini, new species.

Li T. \& Sun S.P. 2022. The genus Alexeter Förster (Hymenoptera, Ichneumonidae) in China, with descriptions of three new species. European Journal of Taxonomy 789: 81-103.

https://doi.org/10.5852/ejt.2022.789.1633

\section{Introduction}

Alexeter Förster, 1869, belonging to the tribe Mesoleiini of the subfamily Ctenopelmatinae (Hymenoptera: Ichneumonidae), comprises 35 species (Yu et al. 2016; Sheng et al. 2020), of which 14 are from the Eastern Palaearctic Region (seven of them also occur in the Western Palaearctic Region) (Uchida 1930, 1952; Šedivý 1971; Yu et al. 2016; Sun et al. 2019; Sheng et al. 2020), 18 from the Western Palaearctic (Meyer 1936; Heinrich 1949, 1953; Hinz 1996; Aubert 1998), three from the Neotropical Region (Gauld et al. 1997), seven from the Nearctic Region (Yu et al. 2016), and one from Oriental Region (also occuring in the Eastern Palaearctic Region) (Luo et al. 2019).

Sun et al. (2019) reported one new species of Alexeter from Beijing, China. Subsequently, 11 species from China were reported by Sheng et al. (2020), of which two were new to science.

The known hosts of Alexeter are sawflies, including Aglaostigma sp., Diprion pini (Linnaeus, 1758), Gilpinia spp., Nematus ferrugineus Förster, 1854, Nematus septentrionalis (Linnaeus, 1758), Rhadinoceraea sp., Rhogogaster spp., Strongylogaster spp., Tenthredopsis spp. (Diprionidae and Tenthredinidae) (Hinz 1961, 1996; Constantineanu \& Istrate 1973; Gauld et al.1997; Aubert 2000; Yu et al. 2016; Sheng et al. 2020). 
In the last three years, the authors have been exploring the National Natural Reserves and Forests in Beijing and Sichuan, situated near the southern border of the Eastern Palaearctic part of China, and Jiangxi, Guizhou near the northern border of the Oriental part of China, and have collected large numbers of ichneumonids. In this paper three new species of Alexeter are described.

\section{Material and methods}

\section{Institutional abbreviations}

GSFGPM = General Station of Forest and Grassland Pest Management, National Forestry and Grassland Administration, P.R. China

KPMNH = Kanagawa Prefectural Museum of Natural History, Odawara, Japan

NHMUK $\quad=\quad$ Natural History Museum, London, United Kingdom

SEHU $\quad=\quad$ Systematic Entomology, Hokkaido University, Japan

ZSM = Zoologische Staatssammlung München, Munich, Germany

\section{Specimen collection}

Direct collection

Specimens were collected by interception traps (IT) (Li et al. 2012) mostly in the National Natural Reserves in Beijing, Guizhou, Jiangxi, Sichuan, China.

\section{Examined material}

Specimens of Alexeter provided by Dr. Gavin Broad (NHMUK) (A. clavator (Müller, 1776) 1 , A. coxalis (Brischke,1871) 1ㅇ, A. multicolor (Gravenhorst, 1829) 1 $ᄋ$, A. nebulator (Thunberg, 1822)

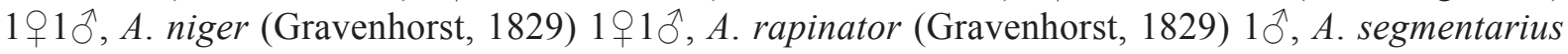
(Fabricius, 1787) 29+9), and by Drs Stefan Schmidt and Olga Schmidt (ZSM) (A. segmentarius (Fabricius, 1787) 1 9 ) were checked. Photos of the types of A. angularis (Uchida, 1952) (19), A. daisetsuzanus Uchida, 1930 (1) and A. shakojiensis Uchida, 1930 (10), deposited in SEHU, taken by Dr. Kyohei Watanabe (KPMNH), were examined and compared to the new species by the corresponding author.

\section{Images}

Images were taken using a Leica M205A stereo microscope with LAS Montage MultiFocus. The final images were edited in Adobe Photoshop CC. Morphological terminology is mostly based on Broad et al. (2018). All examined specimens including holotypes and paratypes are deposited in the Insect Museum, GSFGPM.

\section{Results}

Class Insecta Linnaeus, 1758

Order Hymenoptera Linnaeus, 1758

Superfamily Ichneumonoidea Latreille, 1802

Family Ichneumonidae Latreille, 1802

Subfamily Ctenopelmatinae Förster, 1869

Tribe Mesoleiini Thomson, 1883

Genus Alexeter Förster, 1869

Alexeter Förster, 1869 (1868): 199. Type-species: Mesoleptus ruficornis Gravenhorst, 1829 (= segmentarius Fabricius, 1787). Designated by Viereck (1914).

Zemiophron Förster, 1868: 206. Type-species: Mesoleius laevissimus Strobl, 1903. Designated by Perkins (1962). 


\section{Diagnosis}

The diagnosis of the genus was modified from Gauld et al. (1997), Townes (1970) and Sun et al. (2019).

Clypeus separated from face, usually transversely convex medially; apical margin slightly concave or truncate centrally. Occipital carina reaching hypostomal carina distinctly above base of mandible. Notaulus nearly always long and sharp. Mesopleuron with fine to relatively large punctures. Areolet present, or 3rs-m absent (Gauld et al. 1997). Hind wing vein 1-cu longer than cu-a. First metasomal tergite slender, latero-median carina absent, or very weak and indistinct basally. Glymma present. Second metasomal tergite with fine, or indistinct punctures. Ovipositor with a distinct dorsal subapical notch.

\section{Key to species of Alexeter Förster, 1869 known from China}

1. Mesosoma and metasoma reddish brown, or at most apical portion of metasoma dark brown. Head entirely yellowish brown, at most gena and vertex partly brownish black. Legs entirely yellowish brown to reddish brown.

- Mesosoma black; metasoma at least first metasomal tergite black. Fore and mid legs mostly black, or yellow to reddish brown......

2. Postocellar line $1.3 \times$ as long as ocular-ocellar line. Lateromedian longitudinal carinae of propodeum more or less present; area petiolaris complete. Third metasomal tergite $1.3 \times$ as long as posterior width. Gena, vertex and frons entirely yellowish brown.....

A. clavator (Müller, 1776)

- Postocellar line as long as ocular-ocellar line. Lateromedian longitudinal carinae of propodeum entirely absent; area petiolaris incomplete, anterior side open. Third tergite $0.9 \times$ as long as posterior width. Gena, vertex and frons black. A. nebulator (Thunberg, 1822)

3. Metasomal tergites yellowish brown, or at least some tergites brown to reddish brown 11

- Metasomal tergites black, at most with yellowish white or yellowish brown spots . .4

4. Lateromedian longitudinal carinae of propodeum distinctly convergent anteriorly. Antenna with white ring. Face white..... A. albimaculatus Sheng, Sun \& Li, 2020

- Lateromedian longitudinal carinae of propodeum distinctly narrowed medially. Antenna without white ring, or if with white ring, then face black. Face black or yellow ......

5. Median portions of lateromedian longitudinal carinae combined as single carina (Fig. 20). Metasomal sternites whitish yellow; third tergite with median triangular yellowish white spot

A. flaviventris Li \& Sun sp. nov.

- Median portions of lateromedian longitudinal carinae normal, distinctly separated. Metasomal sternites with lateral longitudinal black spots; all tergites black, at most posterior margins narrowly white

6. Fore wing areolet absent. Head, masosoma and all metasomal tergites entirely black, at most clypeus and mandibular teeth with brownish black spots. All coxae, hind trochanter and femur black

A. melanicus Li \& Sun sp. nov.

- Fore wing areolet present. Head, masosoma and metasomal tergites with yellow or white spots. Fore and mid coxae and trochanters yellow; hind coxa red or black.

7. Lateromedian longitudinal carinae of propodeum absent. Ventral profile of antenna reddish brown. Face yellow. 8

- Lateromedian longitudinal carinae of propodeum present, distinct. Ventral profile of antenna black or almost entirely black. Face black or yellowish white 10 
8. Areolet receiving vein $2 \mathrm{~m}$-cu distinctly basal of or at its lower-posterior corner. Second metasomal tergite $1.2 \times$ as long as posterior width. Fore and mid coxae almost entirely black ......

A. niger (Gravenhorst, 1829)

- Areolet receiving vein $2 \mathrm{~m}$-cu at or almost at its lower-posterior corner. Second metasomal tergite at most $1.0 \times$ as long as posterior width. Fore and mid coxae yellow

9. First metasomal tergite $1.8-1.9 \times$ as long as posterior width. Second metasomal tergite $0.8 \times$ as long as posterior width. Ovipositor sheath distinctly narrowed posteriorly. Hind coxa and femur red ......

A. multicolor (Gravenhorst, 1829)

- First metasomal tergite $2.4 \times$ as long as posterior width (Fig. 9). Second metasomal tergite $1.0 \times$ as long as posterior width (Fig. 10). Ovipositor sheath symmetrical, upper and lower margins parallel (Fig. 11). Hind coxa and femur black

A. flavicoxa Li \& Sun sp. nov.

10. Areolet almost without petiole. Ovipositor sheath distinctly narrowed posteriorly. Hind leg entirely black.

A. angularis (Uchida, 1952)

- Areolet with long petiole. Ovipositor sheath symmetrical, upper and lower margins parallel. Basal portion of hind tibia widely white. Hind tarsomeres $2-4$ white A. beijingensis Sheng, 2019

11. Scutellum, postscutellum, hind coxa, trochanter and femur and all tergites reddish brown. Hind tarsus pale yellow A. shakojiensis Uchida, 1930

- Scutellum, postscutellum, hind coxa, trochanter and femur, metasoma, at least first metasomal tergite, almost entirely black. Hind tarsus black or dark brown

12. Fore wing without areolet. Anterior-lateral portion of mesoscutum with large yellow spot. Fourth and subsequent tergites reddish brown A. zangicus Sheng, Sun \& Li, 2020

- Fore wing with areolet. Mesoscutum entirely black. Fourth and subsequent tergites black 13

13. Subapical portion of clypeus transversely convex, apical margin slightly concave medially. Lateromedian longitudinal carinae of propodeum distinct, narrowed medially. Face entirely black, or yellow laterally. Maxillary and labial palpi almost black.

A. fallax (Holmgren, 1857)

- Median portion of clypeus transversely convex, apical margin truncate. Lateromedian longitudinal carinae of propodeum indistinct, partly absent. Face yellow or with black spot. Maxillary and labial palpi brown

A. segmentarius (Fabricius, 1787)

\author{
Alexeter flavicoxa sp. nov. \\ urn:lsid:zoobank.org:act:E9DCA15D-3F5F-4044-817A-5E9275A6E69C
}

Figs $1-11$

\title{
Diagnosis
}

Face (Fig. 2) Approximately $1.4 \times$ as wide as long. Malar space $0.4 \times$ as long as basal width of mandible. Areolet (Fig. 7) obliquely quadrilateral, with short petiole, receiving vein $2 \mathrm{~m}$-cu almost at its lowerposterior corner. Lateromedian longitudinal carinae of propodeum indistinct (Fig. 8); lateral side of posterior transverse carina present. First metasomal tergite (Fig. 9) irregularly shagreened, $2.4 \times$ as long as posterior width. Fore and mid coxae (Fig. 1) almost entirely whitish yellow.

\section{Differential diagnosis}

The new species is similar to A. niger (Gravenhorst, 1829), but can be distinguished from the latter by the following combination of characters: areolet receiving vein $2 \mathrm{~m}-\mathrm{cu}$ almost at its lower-posterior corner; area petiolaris of propodeum smooth, shiny; second metasomal tergite about as long as posterior width; fore and mid coxae almost entirely whitish yellow. Alexeter niger: areolet receiving vein $2 \mathrm{~m}$-cu 
distinctly basal of its lower-posterior corner; area petiolaris evidently rough; second metasomal tergite $1.2 \times$ as long as posterior width; fore and mid coxae almost entirely black.

\section{Etymology}

The specific name is derived from the whitish yellow fore and mid coxae.

\section{Material examined}

\section{Holotype}

CHINA • ; Sichuan Province, Jiuzhaigou National Nature Reserve, Zechawa; 280 m a.s.1.; 7 Jul. 2020; interception trap; GSFGPM.

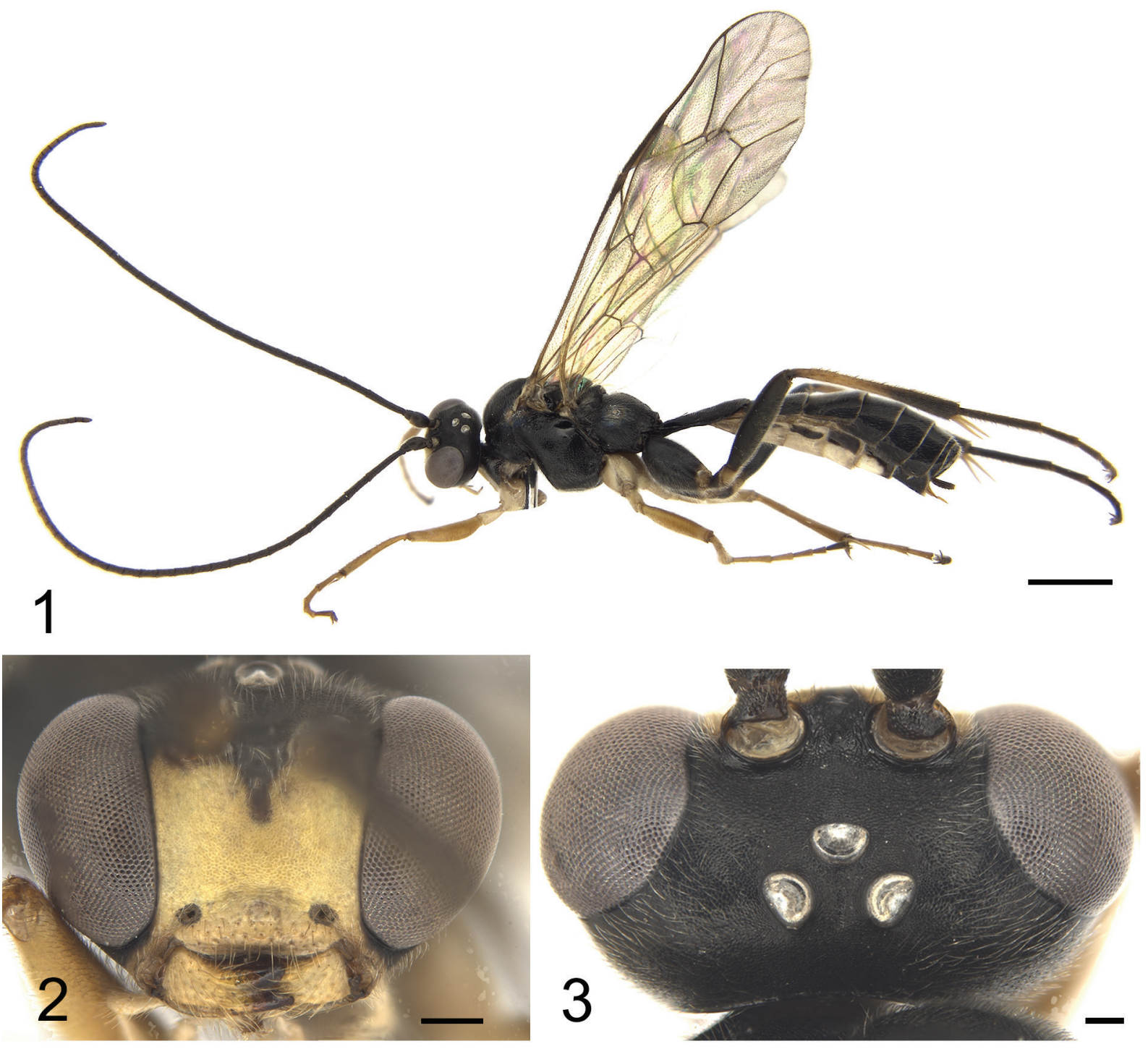

Figs 1-3. Alexeter flavicoxa sp. nov., holotype, $q$ (GSFGPM). 1. Habitus, lateral view. 2. Head, anterior view. 3. Head, dorsal view. Scale bars: $1=2 \mathrm{~mm} ; 2=0.2 \mathrm{~mm} ; 3=0.1 \mathrm{~mm}$. 


\section{Description}

\section{Female}

MeAsurements. Body (Fig. 1). length approximately $13.4 \mathrm{~mm}$. Fore wing length approximately $11.2 \mathrm{~mm}$. Ovipositor sheath length approximately $0.4 \mathrm{~mm}$.

HEAD. Inner orbits (Fig. 2) convergent ventrally. Face approximately $1.4 \times$ as wide as long, slightly convex upper-medially, with dense fine indistinct punctures; upper margin with median emarginated and a small median tubercle. Clypeus $2.7 \times$ as wide as long; shiny, with sparse, distinct punctures and long yellowish brown setae, distance between punctures 2.0-5.0 $\times$ diameter of puncture; strongly convex apically; median portion of apical margin slightly concave. Mandible with distinct punctures and long brownish yellow setae, lower tooth as long as upper tooth. Malar space $0.4 \times$ as long as basal width of mandible. Gena, vertex (Fig. 3) and frons shagreened, with thin, short setae. Genae distinctly convergent posteriorly, with fine indistinct punctures. Postocellar line approximately $0.6 \times$ as long as ocular-ocellar line. Frons slightly evenly concave. Antenna with 36 flagellomeres; ratio of length from first to fifth flagellomeres: 1.8:1.2:1.1:1.0:1.0. Occipital carina complete.
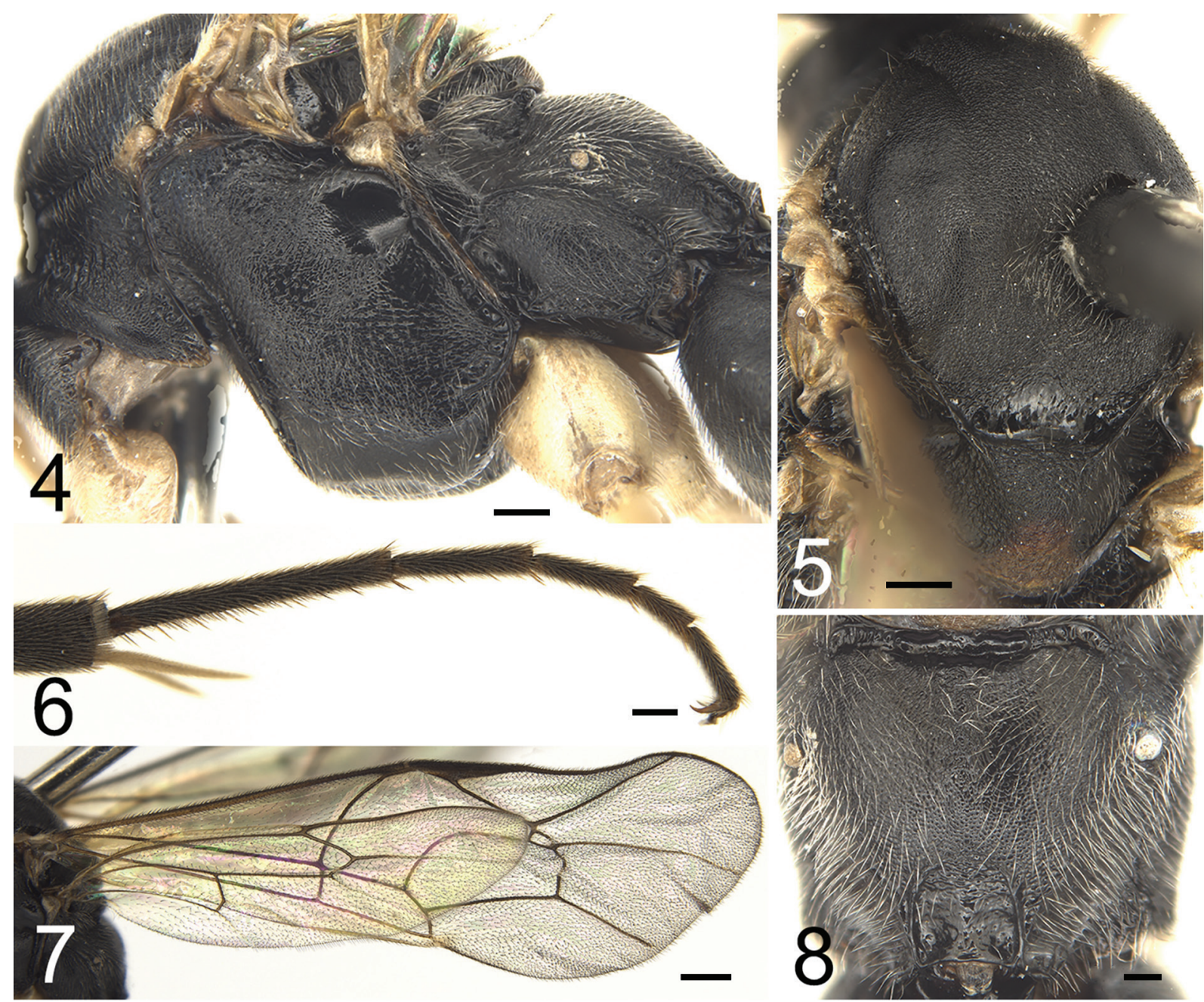

Figs 4-8. Alexeter flavicoxa sp. nov., holotype,, (GSFGPM). 4. Mesosoma, lateral view. 5. Mesoscutum and Scutellum, dorsal-lateral view. 6. Hind yongtarsomeres, lateral view. 7. Wings. 8. Propodeum, dorsal view. Scale bars: $4-6=0.2 \mathrm{~mm} ; 7=0.5 \mathrm{~mm} ; 8=0.1 \mathrm{~mm}$. 
Mesosoma. Pronotum (Fig. 4) shagreened, upper portion of lateral concavity with distinct transverse wrinkles. Mesoscutum shagreened, with distinct punctures. Scutoscutellar groove smooth, shiny. Scutellum distinctly convex, with even, fine punctures. Mesopleuron (Fig. 5) almost shiny, with irregular fine punctures; median portion, in front of speculum, with oblique fine wrinkles; speculum smooth. Upper end of epicnemial carina reaching front margin of mesopleuron. Metapleuron (Fig. 4) evenly convex, shagreened, anterior margin smooth and longitudinally concave. Ratio of length of hind tarsomeres (Fig. 6) from first to fifth: 4.5:2.1:1.6:1.0:1.3. Wings (Fig. 7) slightly gray, hyaline. Fore wing with vein $1 \mathrm{cu}-\mathrm{a}$ distal to M\&RS by not more than $0.2 \times$ length of $1 \mathrm{cu}-\mathrm{a}$. Areolet obliquely quadrilateral, with short petiole, receiving vein $2 \mathrm{~m}$-cu almost at its lower-posterior corner. Postnervulus intercepted almost
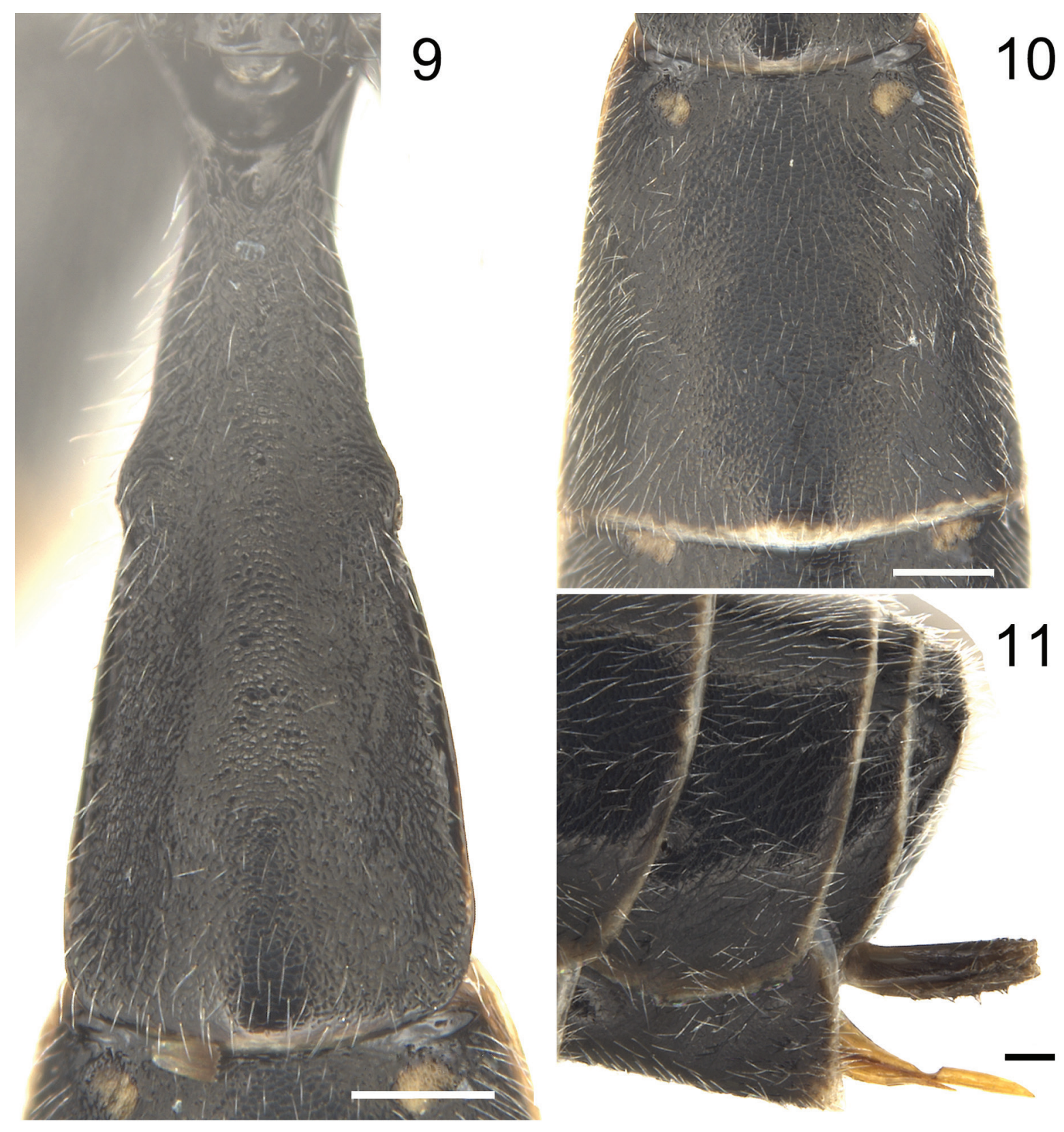

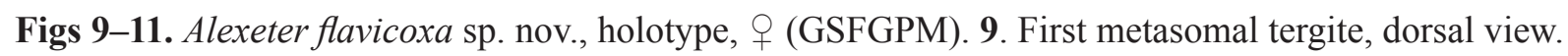
10. Second metasomal tergite, dorsal view. 11. Apical portion of metasoma, lateral view. Scale bars: $9-10=0.2 \mathrm{~mm} ; 11=0.1 \mathrm{~mm}$. 
at middle. Hind wing vein 1 -cu $2.4 \times$ as long as cu-a. Propodeum (Fig. 8 ) evenly convex, shagreened, with dense long gray setae; basal median portion deeply narrowly concave transversely; lateromedian longitudinal carinae indistinct, lateral side of posterior transverse carina present, distinct; area petiolaris small, smooth, shiny. Propodeal spiracle circular, relatively large.

Metasoma. First metasomal tergite (Fig. 9) irregularly shagreened, $2.4 \times$ as long as posterior width, evenly narrowed to base; latero-median carina almost entirely absent; spiracle circular, convex, located at 0.43 of first metasomal tergite. Second metasomal tergite (Fig. 10) shagreened, evenly convex, about as long as posterior width, slightly widened posteriorly; thyridium semicircular, distance to anterior margin of second metasomal tergite less than its diameter. Third and subsequent tergites almost shiny. Ovipositor sheath (Fig. 11) approximately $5.0 \times$ as long as its maximum width, almost parallel laterally. Basal portion of ovipositor (Fig. 11) stout, strongly tapered to dorsal notch; apical portion beyond dorsal notch slender.

Coloration (Fig. 1). Black, except for following: face except upper median small spot, clypeus, mandible except teeth, lower portion of malar area, maxillary palpi, labial palpi, whitish yellow; upper-posterior corner of pronotum, tegula, fore and mid coxae and trochanters, hind trochantellus, posterior margins of second and subsequent tergites narrowly yellowish white. Fore and mid femora, tibiae, tarsi except fifth tarsomeres, yellowish red; basal half except basal end brownish yellow; subtegular ridge, scutellum and postscutellum slightly dark brown. Pterostigma and veins brownish black.

\title{
Male
}

Unknown.

\author{
Alexeter flaviventris sp. nov. \\ urn:1sid:zoobank.org:act:0847F2E8-38C1-4305-97E3-6F4596DEB1B8
}

Figs 12-23

\section{Diagnosis}

Face (Fig. 13) approximately $1.6 \times$ as wide as long. Malar space about $0.4 \times$ as long as basal width of mandible. Median portions of lateromedian longitudinal carinae combined (Fig. 20), length of combined carina as long as area superomedia. First metasomal tergite (Fig. 21) approximately $1.9 \times$ as long as posterior width. Metasomal sternites (Fig. 12) whitish yellow.

\section{Differential diagnosis}

The new species can be easily distinguished from other species of Alexeter by having the median portions of the lateromedian longitudinal carinae of the propodeum combined, the length of the combined carina as long as the area superomedia; metasomal sternites entirely whitish yellow.

\section{Etymology}

The specific name is derived from the whitish yellow metasomal sternites.

\section{Material examined}

Holotype

CHINA • P ; Guizhou Province, Weining, Tuoda Nature Reserve; 2120 m a.s.1.; 20 May 2020; interception trap; GSFGPM.

Paratype

CHINA • 1 क; Beijing, Yanqing, Songshan National Nature Reserve; 18 Aug. 2020; interception trap; GSFGPM. 


\section{Description}

\section{Female}

MeAsurements. Body (Fig. 12) length approximately $7.5 \mathrm{~mm}$. Fore wing approximately $6.6 \mathrm{~mm}$. Ovipositor sheath length approximately $0.5 \mathrm{~mm}$.

HEAD. Inner margins of eyes slightly convergent ventrally. Face (Fig. 13) approximately $1.6 \times$ as wide as long, almost flat, shagreened, upper margin with median V-shaped emargination. Clypeus with sculpture from face, smooth, shiny, approximately $2.9 \times$ as wide as long; with few, fine punctures and brown setae; subapical portion strongly convex; apical margin almost truncate. Mandible with sparse punctures and brown setae; lower tooth as long as upper tooth. Malar space shagreened, with dense yellowish brown setae, about $0.4 \times$ as long as basal width of mandible. Gena (Fig. 15) finely shagreened, evenly

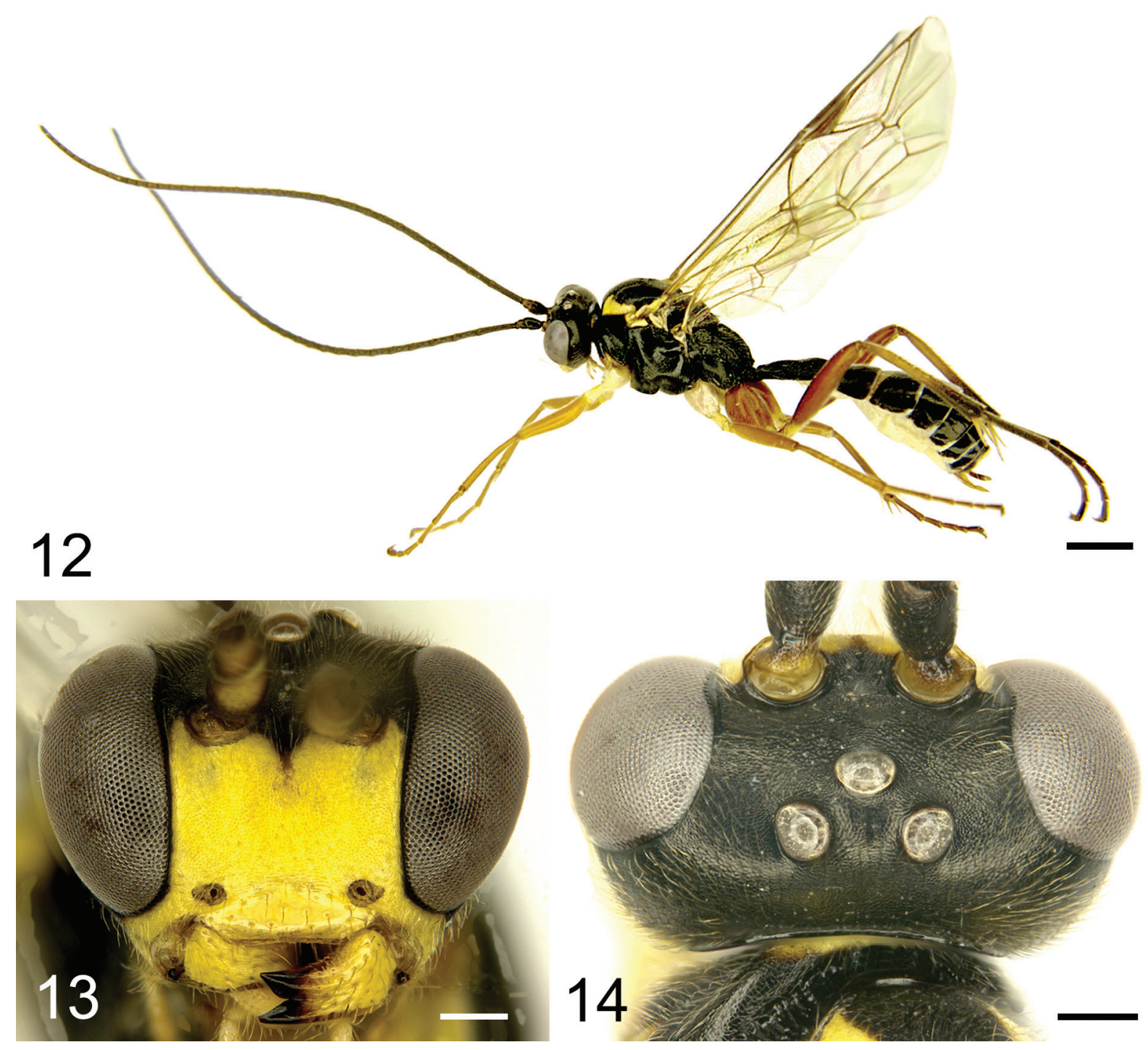

Figs 12-14. Alexeter flaviventris sp. nov., holotype, $९$ (GSFGPM). 12. Habitus, lateral view. 13. Head, anterior view. 14. Head, dorsal view. Scale bars: $12=1 \mathrm{~mm} ; 13-14=0.2 \mathrm{~mm}$. 
convergent backward. Vertex (Fig. 14) with sculpture as gena. Postocellar line approximately $0.9 \times$ as long as ocular-ocellar line. Frons slightly concave above antennal socket, shagreened. Antenna with 37 flagellomeres; ratio of length from first to fifth flagellomeres: 1.7:1.2:1.1:1.1:1.0. Occipital carina complete, joining hypostomal carina above base of mandible.

Mesosoma. Pronotum (Fig. 16) unevenly shagreened, upper portion with transverse wrinkles. Mesoscutum (Fig. 17) shagreened, lateral portions and median lobe with fine indistinct punctures, distance between punctures $0.5-2.0 \times$ diameter of puncture. Scutoscutellar groove relatively wide, smooth, shiny. Scutellum evenly convex, shagreened. Anterior portion of postscutellum distinctly concave. Mesopleuron (Fig. 18) unevenly shagreened, subanterior and lower portion with weak fine punctures, distance between punctures 1.5-5.0 $\times$ diameter of puncture. Speculum smooth, shiny, without sculpture. Upper end of epicnemial carina reaching front edge of mesopleuron and to 0.7 distance to

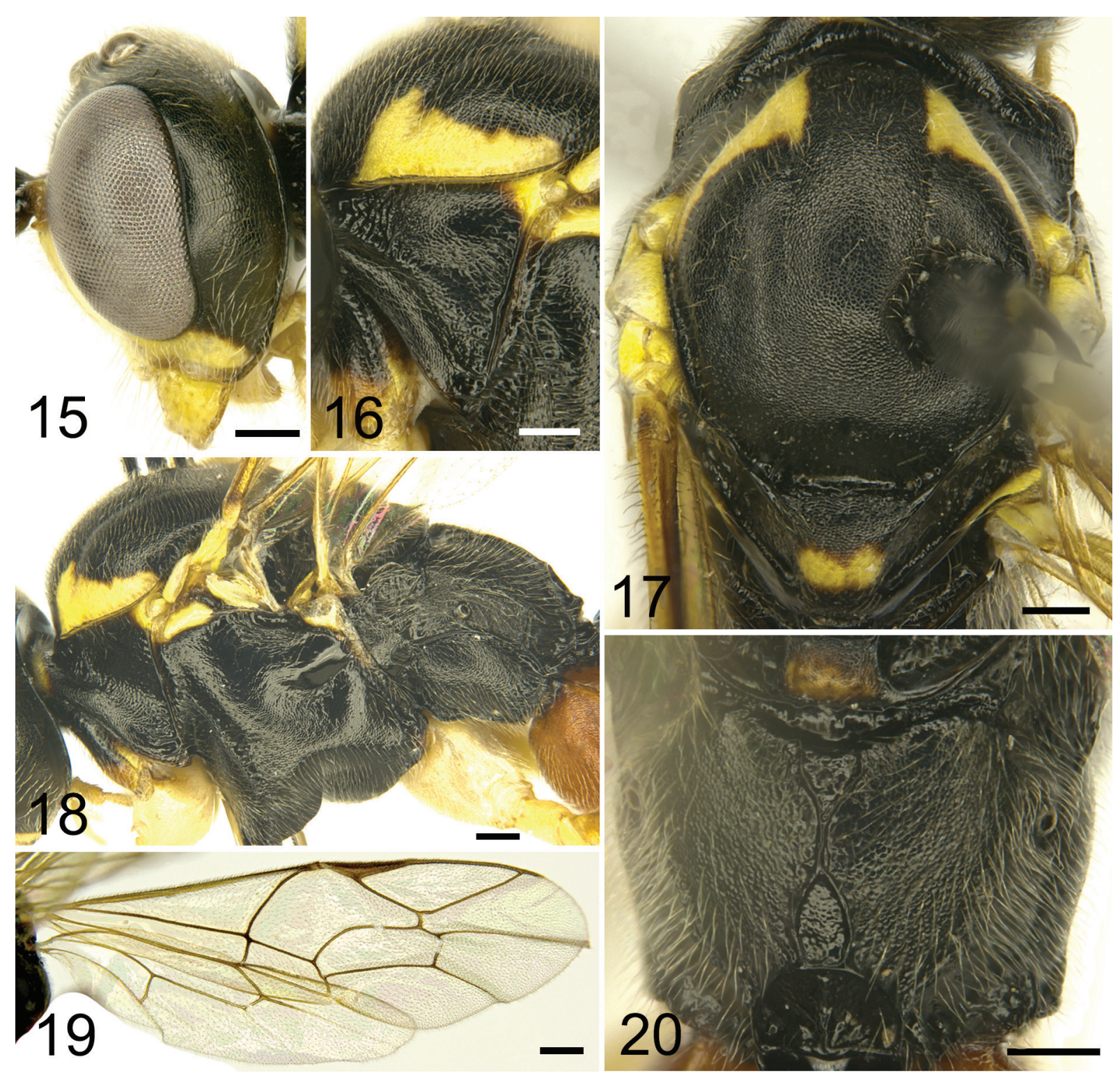

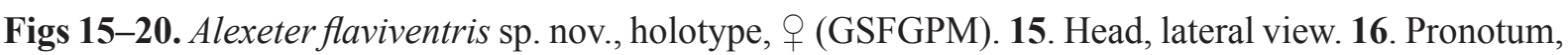
anterior view. 17. Mesoscutum and scutellum, dorsal view. 18. Mesosoma, lateral view. 19. Wings. 20. Propodeum, dorsal view. Scale bars: $15-18,20=0.2 \mathrm{~mm} ; 19=0.5 \mathrm{~mm}$. 
subtegular ridge. Metapleuron slightly convex, sculpture as lower portion of mesopleuron. Ratio of length of hind tarsomeres from first to fifth: 4.5:2.1:1.6:1.0:1.3. Wings (Fig. 19) hyaline. Fore wing with vein $1 \mathrm{cu}-\mathrm{a}$ distal to $\mathrm{M} \& \mathrm{RS}$ by $0.2 \times$ length of $1 \mathrm{cu}-\mathrm{a}$. Areolet absent. Distance from vein $2 \mathrm{rs}-\mathrm{m}$ to $2 \mathrm{~m}$-cu $1.5 \times$ length of $2 \mathrm{rs}-\mathrm{m}$. Postnervulus intercepted at middle. Hind wing vein $1-\mathrm{cu} 1.5 \times$ as long as cu-a. Propodeum (Fig. 20) evenly convex, with dense gray setae, sublateral portion shagreened; lateromedian longitudinal carinae and posterior transverse carinae complete, strong. Median portions of lateromedian longitudinal carinae combined, length of combined carina as long as area superomedia. Area basalis triangular. Area superomedia reversed triangular. Propodeal spiracle small, circular.

Metasoma. First metasomal tergite (Fig. 21) approximately $1.9 \times$ as long as posterior width, evenly narrowed anteriorly, shagreened, posterior margin smooth; latero-median carina almost entirely absent; dorso-lateral carinae distinct, complete except near spiracle; ventro-lateral carina distinct, complete; spiracle circular, located approximately at 0.4 of first metasomal tergite. Glymma large, deep. Second (Fig. 22) and subsequent tergites shagreened. Second metasomal tergite $0.7 \times$ as long as posterior width; thyridium small, transversely elliptical. Upper and lower margins of ovipositor sheath (Fig. 23) almost parallel. Ovipositor (Fig. 23) relatively strong, compressed, subapical dorsal notch relatively deep and sharp.

Coloration (Fig. 12). Black, except for following: face, clypeus, mandible except teeth, maxillary palpi, labial palpi, ventral profile of pedicel, ventral apical half of scape, upper-posterior corners of pronotum, tegulae, anterolateral portion of mesoscutum, subtegular ridge, posterior portion of scutellum,
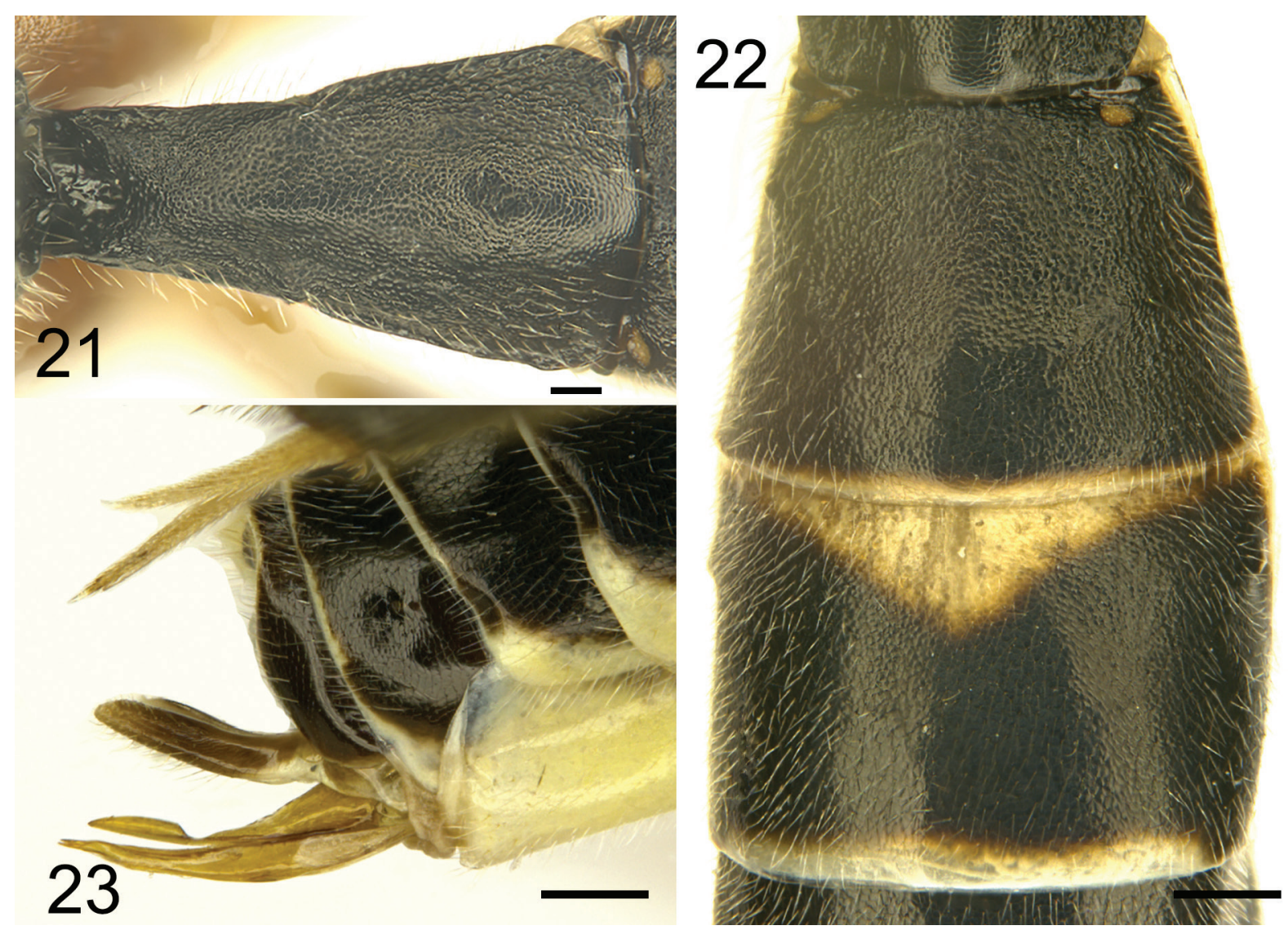

Figs 21-23. Alexeter flaviventris sp. nov., holotype, $q$ (GSFGPM). 21. First metasomal tergite, dorsal view. 22. Second and third tergites, dorsal view. 23. Apical portion of metasoma, lateral view. Scale bars: $21=0.1 \mathrm{~mm} ; 22-23=0.2 \mathrm{~mm}$. 
postscutellum slightly, fore and mid coxae and all trochanters, metasomal sternites whitish yellow. Fore and mid femora yellowish brown, tibiae and tarsi and basal half of hind tibiae except basal end darkbrownish yellow. Hind coxa and femur brownish red. Posterior margin of second metasomal tergite and anterior median triangular sport of third tergite yellow. Posterior margins of third and subsequent tergites narrowly white. Pterostigma and veins blackish brown.

\author{
Male \\ Unknown. \\ Alexeter melanicus sp. nov. \\ urn:1sid:zoobank.org:act:5CAC94F3-CD1B-4D39-8233-2A044AA3F29A
}

Figs 24-34

\title{
Diagnosis
}

Face (Fig. 25) approximately $1.5 \times$ as wide as long, with dense indistinct punctulate-reticulate sculpture. Malar space about $0.3 \times$ as long as basal width of mandible. Areolet (Fig. 30) absent; distance between $2 \mathrm{rs}-\mathrm{m}$ and $2 \mathrm{~m}-\mathrm{cu} 1.1 \times$ as long as $2 \mathrm{rs}-\mathrm{m}$. Lateromedian longitudinal carinae of propodeum (Fig. 31) strong, distinctly narrowed medially; area between lateromedian longitudinal carinae shiny, with indistinct irregular wrinkles. First metasomal tergite (Fig. 32) approximately $2.0 \times$ as long as posterior width.

\section{Differential diagnosis}

The new species is similar to A. angularis (Uchida, 1952), but can be distinguished from the latter by the following combination of characters: clypeus shiny, with relatively dense, distinct punctures; areolet absent; ventral profile of mid tarsomeres yellowish white, dorsal profiles brown; hind tarsomeres 1-4 yellowish white. Alexeter angularis: clypeus shagreened, with very sparse fine punctures; areolet present; mid and hind tarsi entirely black.

\section{Etymology}

The specific name is derived from the almost entirely black body.

\section{Material examined}

\section{Holotype}

CHINA • ; Guizhou Province, Jiangkou, Fanjingshan National Nature Reserve, Lengjiaba; 840 m a.s.l.; 15 June 2019; interception trap; GSFGPM.

\section{Paratypes}

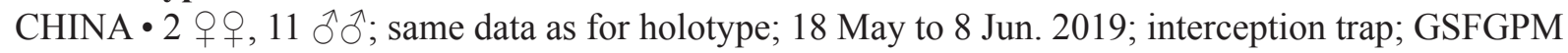
- 1 ; s same data as for holotype; 1250 m a.s.1.; 15 may 2019; interception trap; GSFGPM.

\section{Description}

\section{Female}

Measurements. Body (Fig. 24) length 12.4-14.1 mm. Fore wing length 9.9-11.3 mm. Ovipositor sheath length $0.5-0.6 \mathrm{~mm}$.

HEAD. Inner orbits almost parallel, slightly concave near antennal sockets. Face (Fig. 25) approximately $1.5 \times$ as wide as long, with dense indistinct punctulate-reticulate sculpture; sides and median portion slightly evenly convex; upper margin indistinct, with median small tubercle. Clypeus shiny, approximately $2.9 \times$ as wide as long, with relatively large punctures (Fig. 25); apical margin almost truncate. Mandible shagreened, with brownish yellow setae; teeth smooth, upper tooth distinctly shorter than lower tooth. 
Malar space shagreened, about $0.3 \times$ as long as basal width of mandible, with brownish yellow setae. Gena finely shagreened, evenly convergent posteriorly, with fine indistinct punctures. Vertex (Fig. 26) with sculpture as gena; postocellar line approximately $0.7 \times$ as long as ocular-ocellar line. Frons slightly evenly concave, finely shagreened. Antenna with 44-49 flagellomeres; ratio of length from first to fifth flagellomeres approximately: 2.4:1.1:1.1:1.0:1.0. Occipital carina complete, lower end joining hypostomal carina above base of mandible.

Mesosoma. Anterior and upper-posterior portions of pronotum (Fig. 27) shagreened, with fine punctures; upper portion of lateral concavity with distinct transverse wrinkles. Mesoscutum (Fig. 28) finely shagreened. Notauli weak. Scutoscutellar groove almost shiny. Scutellum distinctly convex, with fine indistinct punctures. Postscutellum shagreened, anterior margin transversely deeply concave. Mesopleuron (Fig. 27) almost flat, shagreened; anterior portion and along upper margin with fine punctures; speculum smooth, upper portion with sparse indistinct punctures. Upper end of epicnemial carina approximately reaching 0.4 distance to subtegular ridge. Metapleuron slightly convex, with sculpture mainly as mesopleuron; lower posterior portion with short indistinct wrinkles; submetapleural carina complete, anterior portion strongly

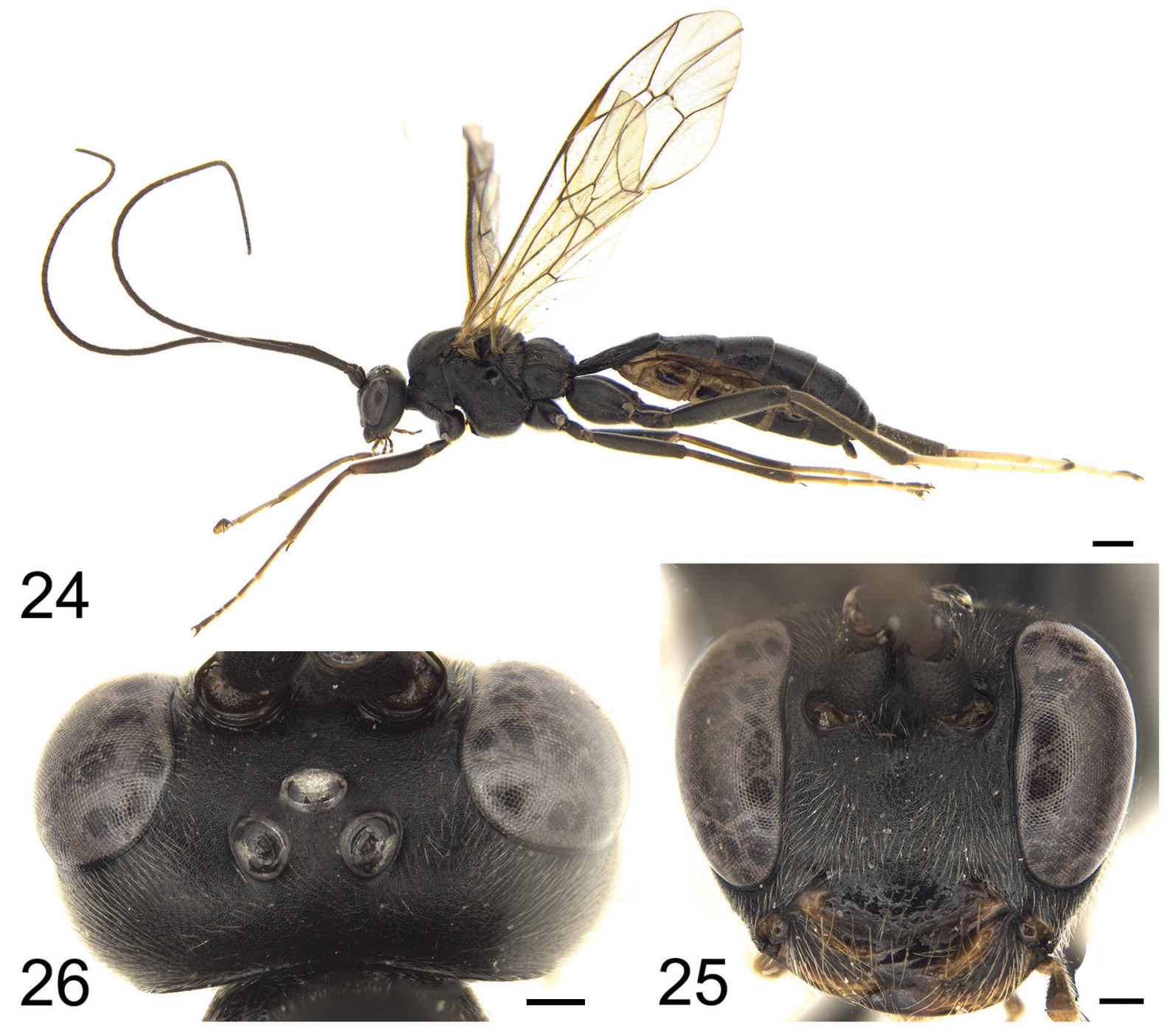

Figs 24-26. Alexeter melanicus sp. nov., holotype, $q$ (GSFGPM). 24. Habitus, lateral view. 25. Head, anterior view. 26. Head, dorsal view. Scale bars: $24=1 \mathrm{~mm} ; 25-26=0.2 \mathrm{~mm}$. 
convex. Ratio of length of hind tarsomeres (Fig. 29) from first to fifth approximately: 4.7:2.3:1.7:1.0:1.2. Wings (Fig. 30) slightly brownish, hyaline. Fore wing with vein 1cu-a distal to M\&RS by approximately $0.3 \times$ length of $1 \mathrm{cu}-\mathrm{a}$. Areolet absent. Distance between $2 \mathrm{rs}-\mathrm{m}$ and $2 \mathrm{~m}-\mathrm{cu} 1.1 \times$ as long as $2 \mathrm{rs}-\mathrm{m}$. Postnervulus intercepted at middle. Hind wing vein 1-cu $2.3 \times$ as long as cu-a. Propodeum (Fig. 31) evenly convex, finely shagreened, with dense brownish white setae; lateromedian longitudinal carinae strong, distinctly narrowed medially, area between lateromedian longitudinal carinae shiny, with indistinct irregular wrinkles; area petiolaris shiny, with indistinct longitudinal wrinkles. Propodeal spiracle oblique elliptical.

Metasoma. First metasomal tergite (Figs 32-33) approximately $2.0 \times$ as long as posterior width, strongly and evenly narrowed to base; almost shiny; base deeply concave medially; with irregular fine punctures; anterior portion of latero-median carina along median concavity present; dorso-lateral carinae almost complete; spiracle circular, small, located approximately at middle of first metasomal tergite. Second metasomal tergite (Fig. 32) approximately $0.8 \times$ as long as apical width; anterior portion slightly rough, finely indistinctly punctate; posterior portion with fine distinct punctures. Third and subsequent tergites almost shiny. Third and fourth tergites with fine distinct punctures. Ovipositor sheath (Fig. 34) approximately $3.1 \times$ as long as its width, slightly widened medially. Ovipositor (Fig. 34) compressed, with subapical dorsal notch.

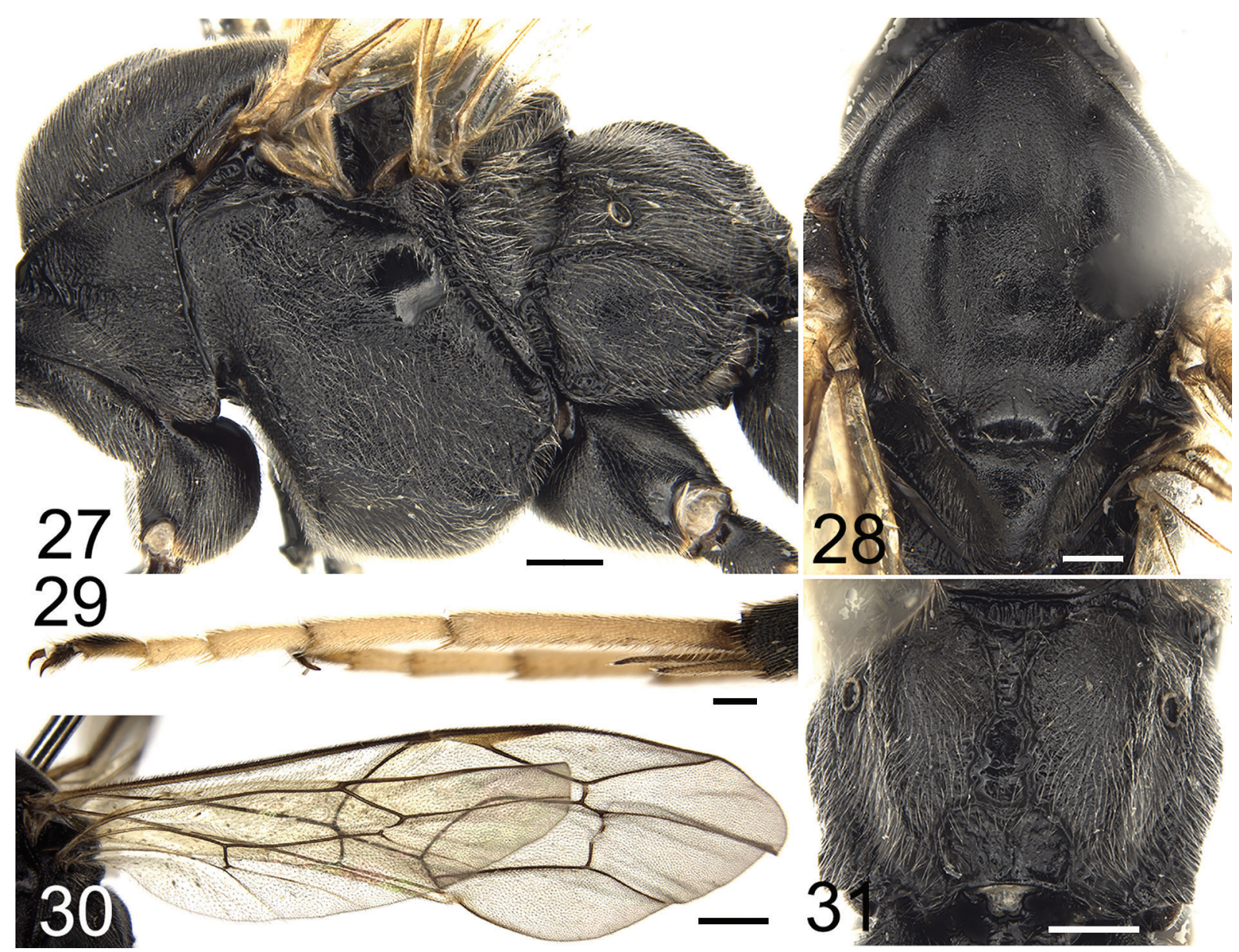

Figs 27-31. Alexeter melanicus sp. nov., holotype, + (GSFGPM). 27. Mesosoma, lateral view. 28. Mesoscutum and scutellum, dorsal view. 29. Hind tarsomeres, lateral view. 30. Wings. 31. Propodeum, dorsal view. Scale bars: $27,31=0.4 \mathrm{~mm} ; 28-29=0.3 \mathrm{~mm} ; 30=1 \mathrm{~mm}$. 
Coloration (Fig. 24). Black, except for following: lateral portion of clypeus, upper and lower median portions of mandible yellowish brown. Maxillary and labial palpi darkish brown. Dorsal profile and apex of fore femur red brown. Ventral profiles of fore tibia and tarsomeres yellowish brown. Dorsal profiles of fore tibia and tarsomeres dark brown. Ventral profile of mid tibia dark brown; Ventral profile of mid tarsomeres yellowish white, dorsal profiles brown. Hind tarsomeres 1-4 yellowish white, tarsomere 5 mainly dark brown. Pterostigma yellowish brown. Veins brownish black.

\section{Male}

MeAsuREMENTs. Body length 11.6-13.2 mm. Fore wing length 8.6-9.7 mm.

BoDy. Antenna with 42-45 flagellomeres. Black, except for following: face except upper median longitudinal spot, clypeus, mandible except tooth, maxillary and labial palpi, ventral profile of scape, upper-posterior corner of pronotum, anterolateral margin of mesoscutum, tegula, subtegular ridge, posterior margin of tergite 2, median irregular spot of tergite 3 , anterior median triangular spot of tergite 4 yellow to yellowish white. Pterostigma and veins darkish brown. Remainder almost entirely same as female.

VARIATIOn. The clypeus and mandible except teeth brown. Basal portion of hind tibia dark brown.

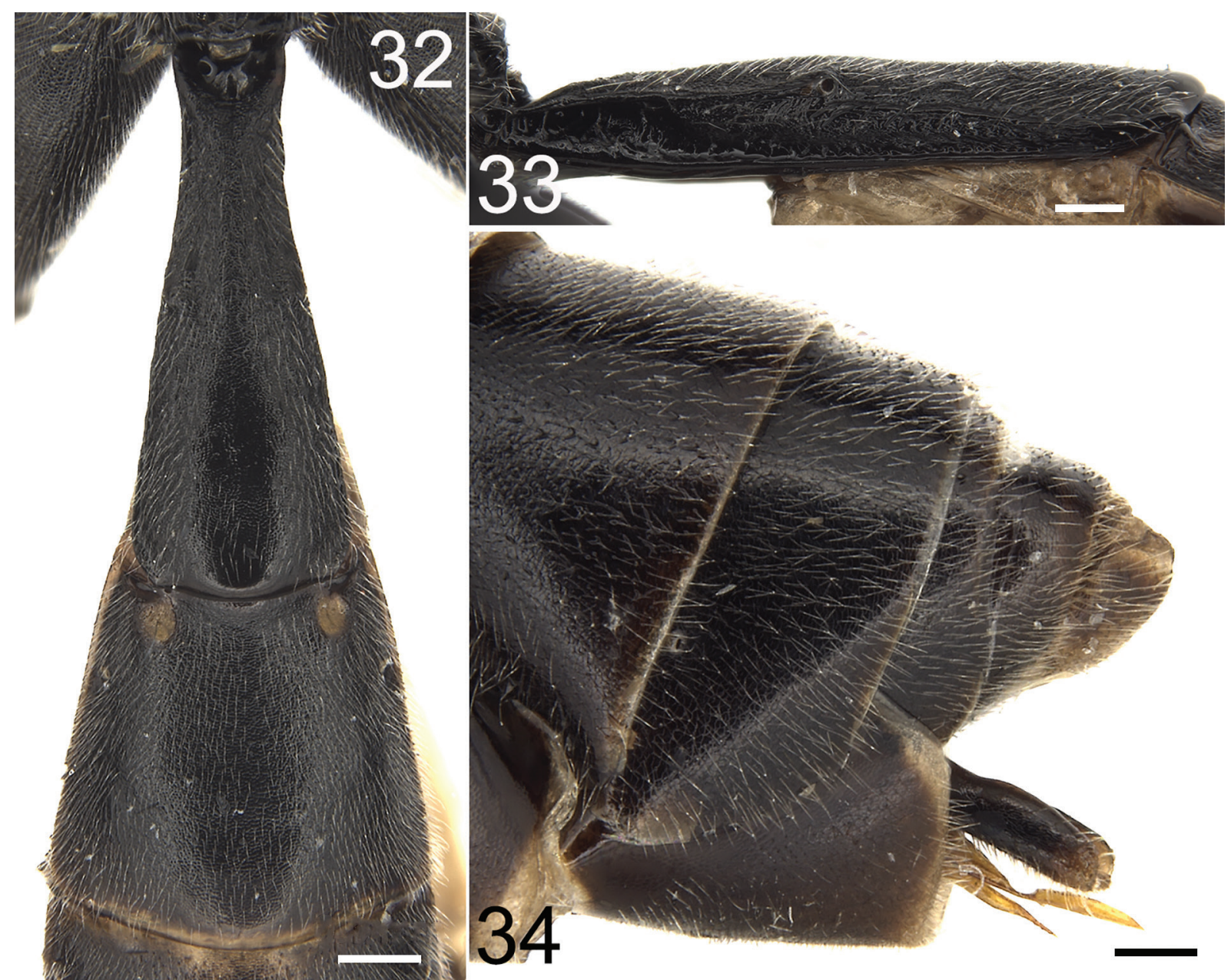

Figs 32-34. Alexeter melanicus sp. nov., paratype, $q$ (GSFGPM). 32. First and second metasomal tergites, dorsal view. 33. First metasomal tergite, lateral view. 34. Apical portion of metasoma, lateral view. Scale bars: $32=0.3 \mathrm{~mm} ; 33-34=0.2 \mathrm{~mm}$. 
Alexeter albimaculatus Sheng, Sun \& Li, 2020

Fig. 35

\section{Diagnosis}

Face approximately $1.5 \times$ as wide as long. Malar space about $0.3 \times$ as long as basal width of mandible. Postocellar line approximately $0.6 \times$ as long as ocular-ocellar line.

Areolet triangular, with long petiole; fore wing with vein 1 cu-a distal to M\&RS by $0.3 \times 1$ length of $1 \mathrm{cu}-\mathrm{a}$; hind wing vein 1 -cu $1.5 \times$ as long as cu-a. Anterior transverse carina of propodeum absent; lateromedian longitudinal carinae distinctly convergent anteriorly. First metasomal tergite approximately $2.4 \times$ as long as posterior width. Face, spots of anterior-lateral portion of mesoscutum, 12 to 19 flagellomeres white.

\section{Material examined}

Holotype

CHINA • क; Mt. Liupan, Ningxia; 18 Aug. 2005; interception trap; GSFGPM.

\section{Paratypes}

CHINA・16 우, 4 $\widehat{\jmath}$; Mt. Liupan, Ningxia; 21 Jul. to 8 Sep. 2005; interception trap; GSFGPM.

Alexeter angularis (Uchida, 1952)

Fig. 36

\section{Diagnosis}

Face approximately $1.4 \times$ as wide as long. Malar space about $0.35 \times$ as long as basal width of mandible. Postocellar line approximately $0.7 \times$ as long as ocular-ocellar line.

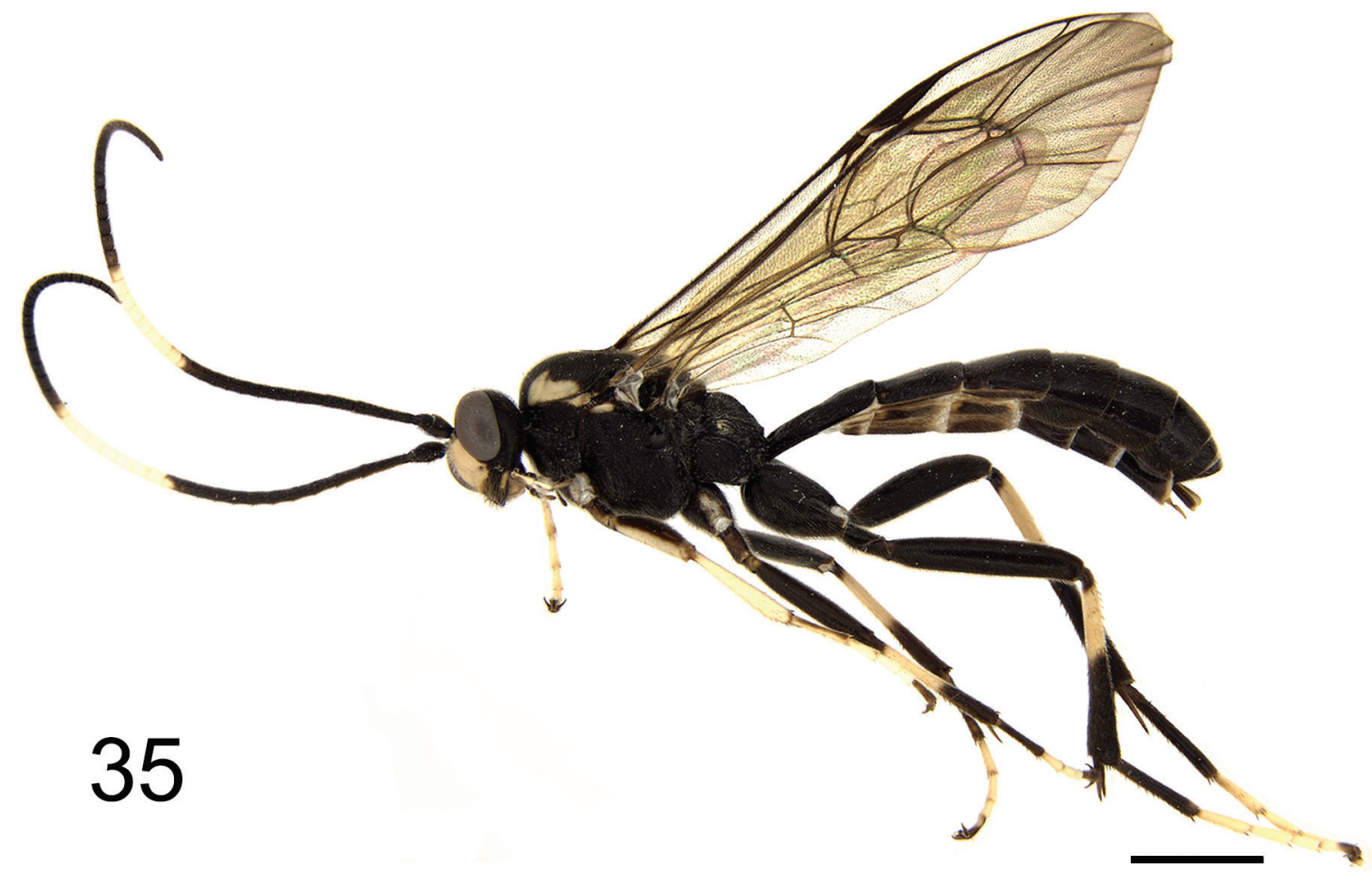

Fig. 35. Alexeter albimaculatus Sheng, Sun \& Li, 2020, paratype, $q$ (GSFGPM), habitus, lateral view. Scale bar: $2 \mathrm{~mm}$. 
Areolet quadrilateral; fore wing with vein $1 \mathrm{cu}-\mathrm{a}$ distal to M\&RS by $0.4 \times$ length of $1 \mathrm{cu}-\mathrm{a}$; hind wing vein 1 -cu $1.5 \times$ as long as cu-a. Lateromedian longitudinal carinae of propodeum distinctly constricted medially. First metasomal tergite approximately $2.6 \times$ as long as posterior width. Fore tibia yellowish white.

\section{Material examined}

CHINA • 1 क; Mentougou, Beijing; 29 Sep. 2009; Tao Wang leg.; GSFGPM.

Alexeter beijingensis Sheng, 2019

\section{Diagnosis}

Face approximately $1.3 \times$ as wide as long. Malar space about $0.5 \times$ as long as basal width of mandible. Postocellar line approximately $0.5 \times$ as long as ocular-ocellar line. Areolet triangular, with long petiole; fore wing with vein $1 \mathrm{cu}-\mathrm{a}$ distal to M\&RS by $0.3 \times$ length of $1 \mathrm{cu}$-a; hind wing vein 1 -cu $1.5 \times$ as long as cu-a. Lateromedian longitudinal carinae of propodeum distinctly constricted medially. First metasomal tergite approximately $2.4 \times$ as long as posterior width. Fore tibia, basal halves of mid and hind tibiae except bases, mid tarsomeres 3 to 4 , hind tarsomeres 2 to 5 (apical half black) white.

\section{Material examined}

\section{Holotype}

CHINA • 1 q; Mentougou, Beijing; 20 Aug. 2004; Shi-Xiang Zong leg.; GSFGPM.

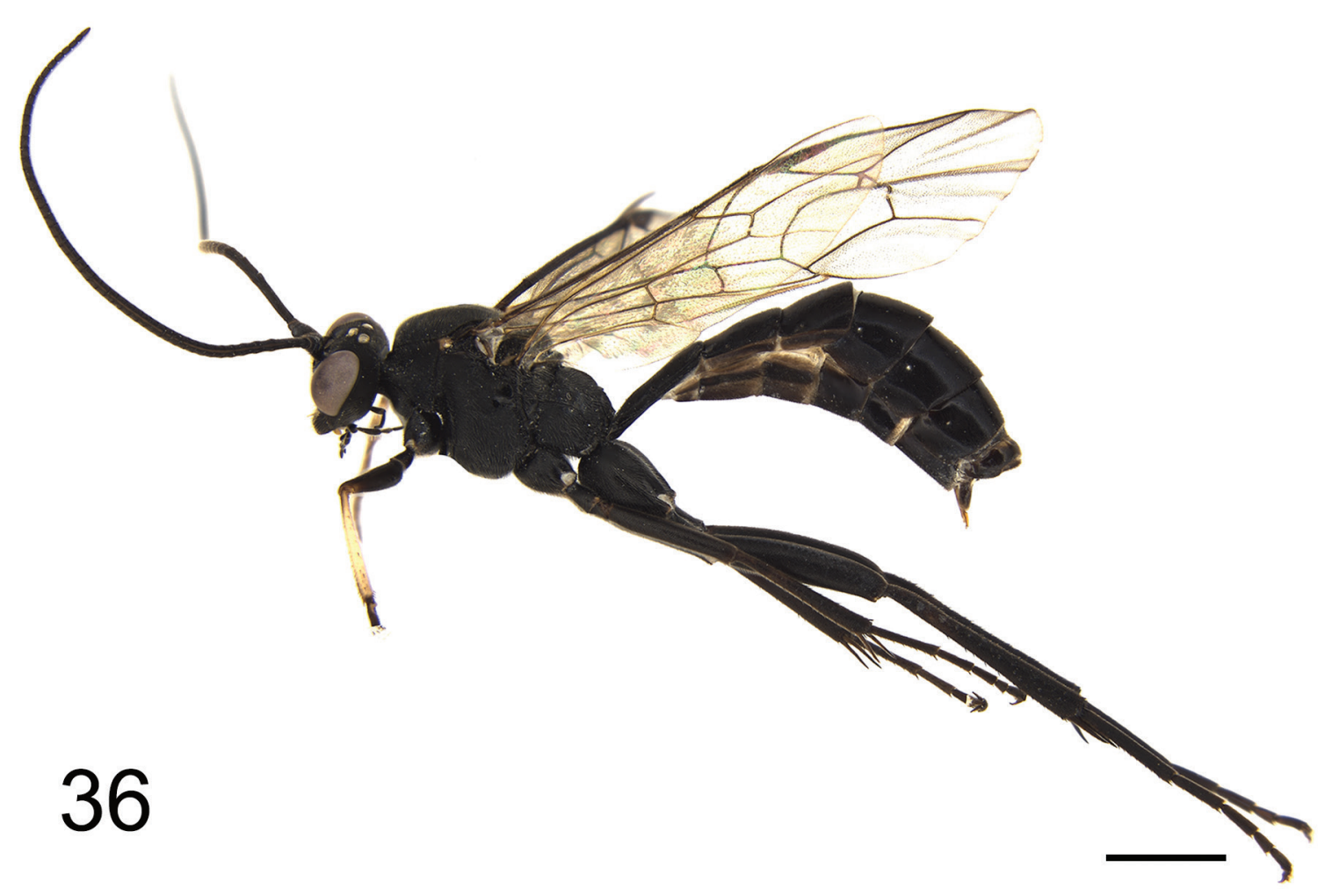

Fig. 36. Alexeter angularis (Uchida, 1952), $q$ (GSFGPM), habitus, lateral view. Scale bar: $2 \mathrm{~mm}$. 
Alexeter clavator (Müller, 1776)

\section{Diagnosis}

Face approximately $1.4 \times$ as wide as long. Malar space about $0.15 \times$ as long as basal width of mandible. Postocellar line approximately $1.3 \times$ as long as ocular-ocellar line. Areolet triangular, with short petiole; fore wing with vein $1 \mathrm{cu}-\mathrm{a}$ distal to M\&RS by $0.2 \times$ length of $1 \mathrm{cu}-\mathrm{a}$; hind wing vein 1 -cu $3.0 \times$ as long as cu-a. Lateromedian longitudinal carinae of propodeum distinct and complete. First metasomal tergite approximately $3.3 \times$ as long as posterior width. Body brown to reddish brown; face, clypeus, mandible (teeth black), gena, tegulae, fore and mid coxae, trochanters white to pale yellow.

\section{Material examined}

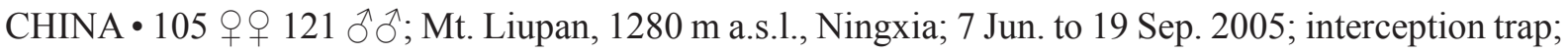
GSFGPM・ 1 q; Mt. Qinling, Shaanxi; 5 Jul. 2017; Tao Li leg.; GSFGPM.

$$
\text { Alexeter fallax (Holmgren, 1857) }
$$

\section{Diagnosis}

Face approximately 1.2 to $1.3 \times$ as wide as long. Malar space about $0.6 \times$ as long as basal width of mandible. Postocellar line approximately $0.7 \times$ as long as ocular-ocellar line. Areolet triangular, with short petiole; fore wing with vein 1cu-a slight distal or opposite to M\&RS; hind wing vein 1-cu $1.5 \times$ as long as cu-a. Lateromedian longitudinal carinae of propodeum distinct, narrowed medially. First metasomal tergite approximately 2.0 to $2.2 \times$ as long as posterior width. Face black, or yellow laterally; Maxillary and labial palpi almost black; tergites 2 to 4 yellowish red.

\section{Material examined}

CHINA • 6 우, 1 § ; Mt. Liupan, Ningxia; 28 Jul. to 1 Sep. 2005; interception trap; GSFGPM.

Alexeter multicolor (Gravenhorst, 1829)

\section{Diagnosis}

Face approximately $1.5 \times$ as wide as long. Malar space about $0.25 \times$ as long as basal width of mandible. Postocellar line approximately $0.7 \times$ as long as ocular-ocellar line. Areolet obliquely quadrilateral, with short petiole; fore wing with vein $1 \mathrm{cu}-\mathrm{a}$ distal to M\&RS by $0.3 \times$ length of $1 \mathrm{cu}-\mathrm{a}$; hind wing vein 1 -cu $2.3 \times$ as long as cu-a. Lateromedian longitudinal carinae of propodeum distinctly expanded medially. First metasomal tergite approximately $1.7 \times$ as long as posterior width. Face, clypeus, tegula, scutellum and postscutellum pale yellow.

\section{Material examined}

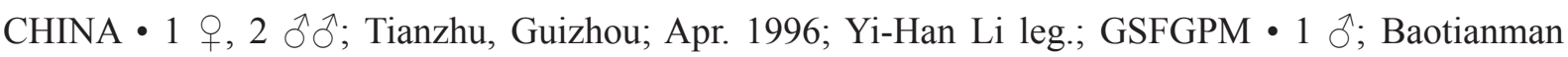
National Natural Reserve, 1300-1500 m a.s.l., Henan; 12 Jul. 1998; Mao-Ling Sheng leg.; GSFGPM

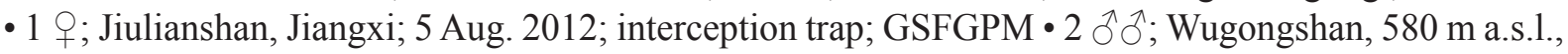
Jiangxi; 16 May 2016; Yu Yao leg.; GSFGPM.

Alexeter nebulator (Thunberg, 1824)

\section{Diagnosis}

Face approximately 1.5 to $1.6 \times$ as wide as long. Malar space about $0.4 \times$ as long as basal width of mandible. Postocellar line approximately $1.0 \times$ as long as ocular-ocellar line. Areolet triangular, with short petiole; fore wing with vein 1cu-a slight distal to M\&RS; hind wing vein 1-cu 1.9 to $2.3 \times$ as long 
as cu-a. Lateromedian longitudinal carinae of propodeum absent. First metasomal tergite approximately 1.6 to $1.7 \times$ as long as posterior width. Body yellowish brown; gena, vertex, frons black.

\section{Material examined}

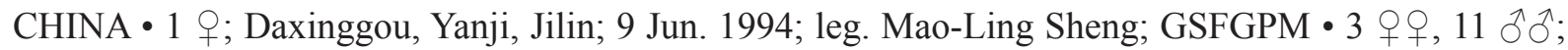
Mt. Liupan, 1280 m, Ningxia; 7 Jul. to 4 Aug. 2005; interception trap; GSFGPM • 2 q ; ; Beijing; 28 Jul. to 4 Aug. 2009; interception trap; GSFGPM • 1 \%; Beijing; 11 Aug. 2010; interception trap; GSFGPM - 1 O; Beijing; 10 Aug. 2013; interception trap; GSFGPM.

Alexeter niger (Gravenhorst, 1829)

\section{Diagnosis}

Face approximately $1.5 \times$ as wide as long. Malar space about $0.2 \times$ as long as basal width of mandible. Postocellar line approximately $0.6 \times$ as long as ocular-ocellar line. Areolet obliquely quadrilateral, with short petiole; fore wing with vein $1 \mathrm{cu}-\mathrm{a}$ distal to M\&RS by $0.3 \times$ length of $1 \mathrm{cu}-\mathrm{a}$; hind wing vein 1 -cu $1.0 \times$ as long as cu-a. Lateromedian longitudinal carinae absent. First metasomal tergite approximately $2.0 \times$ as long as posterior width.

\section{Material examined}

CHINA • 1 क; Baishilazi National Natural Reserve, 1000 m, Kuandian, Liaoning; 3 Jun. 2001; leg. MaoLing Sheng; GSFGPM.

Alexeter segmentarius (Fabricius, 1787)

\section{Diagnosis}

Face approximately $1.4 \times$ as wide as long. Malar space about $0.5 \times$ as long as basal width of mandible. Postocellar line approximately $0.8 \times$ as long as ocular-ocellar line. Areolet triangular; fore wing with vein $1 \mathrm{cu}-\mathrm{a}$ distal of M\&RS; hind wing vein 1 -cu $1.5 \times$ as long as cu-a. Lateromedian longitudinal carinae of propodeum indistinct, partly absent. First metasomal tergite approximately $1.9 \times$ as long as posterior width. Face yellow or with black spot.

\section{Material examined}

CHINA • 1 đ̊; Zhengfengshan, Helong, Jilin; 2 Aug. 1982; Bing-Zong Ren leg.; GSFGPM • 1 o ; Mt. Liupan, Ningxia; 11 Aug. 2005; interception trap; GSFGPM.

\section{Alexeter shakojiensis Uchida, 1930}

Fig. 37

\section{Diagnosis}

Face approximately 1.6 to $1.7 \times$ as wide as long. Malar space about $0.4 \times$ as long as basal width of mandible. Postocellar line approximately 0.6 to $0.7 \times$ as long as ocular-ocellar line. Areolet triangular, with long petiole; fore wing with vein 1cu-a slight distal to M\&RS; hind wing vein 1-cu $2.3 \times$ as long as cu-a. Lateromedian longitudinal carinae of propodeum distinct, almost parallel. First metasomal tergite approximately 2.7 to $2.8 \times$ as long as posterior width. Hind legs (tarsus pale yellow), tergites reddish brown.

\section{Material examined}

CHINA • 1 q; Benxi, Liaoning; 1 Jul. 1993; leg. Zhen-Lu Liu; GSFGPM • 6 q $q$; Mengoutou, Beijing; 29 Aug. to 22 Sept. 2008; Tao Wang leg.; GSFGPM • 1 q, 1 ổ; Mengoutou, Beijing; 4 Aug. to 
8 Sept. 2009; Tao Wang leg.; GSFGPM • 1 क; Zhouzhi, Shaanxi; 4 Aug. 2009; leg. Mao-Ling Sheng; GSFGPM・ 1 ^’; Yanqing, Beijing; 12 Jun. 2012; leg. Shi-Xiang Zong; GSFGPM.

Alexeter zangicus Sheng, Sun \& Li, 2020

Fig. 38

\section{Diagnosis}

Face approximately $1.6 \times$ as wide as long. Malar space about $0.5 \times$ as long as basal width of mandible. Postocellar line approximately $0.8 \times$ as long as ocular-ocellar line. Areolet absent; fore wing with vein 1 cu-a distal to M\&RS by $0.4 \times$ length of $1 \mathrm{cu}-\mathrm{a}$; hind wing vein 1 -cu $4.0 \times$ as long as cu-a. Basal of lateromedian longitudinal carinae of propodeum indistinct and convergent. First metasomal tergite approximately $2.4 \times$ as long as posterior width. Anterior-lateral portion of mesoscutum with large yellow spot. Fourth and subsequent tergites reddish brown.

\section{Material examined}

Holotype

CHINA・19; Baqing, Xizang; 1 Aug. 2013; Tao Li leg.; GSFGPM.

\section{Discussion}

Alexeter melanicus with some characters special: clypeus with apical median notch; dorso-lateral carinae of first metasomal tergite distinct; fore wing vein cu-a is distinctly distal to M\&RS. Most species of Alexeter: clypeus distinctly convex medially or a little below median portion, median portion of apical margin truncate or concave; dorso-lateral carinae of first metasomal tergite at least partly absent; fore wing vein cu-a interstitial or slightly postfurcal. According to the diagnosis of genera of Mesoleiini, this species is mostly close to Alexeter: clypeus distinctly convex transversely almost on median portion, Notauli present, anterior portion distinct, reaching to anterior margin of mesoscutum (Fig. 27); areolet absent; first metasomal tergite (Fig. 32) $2.0 \times$ as long as posterior width.

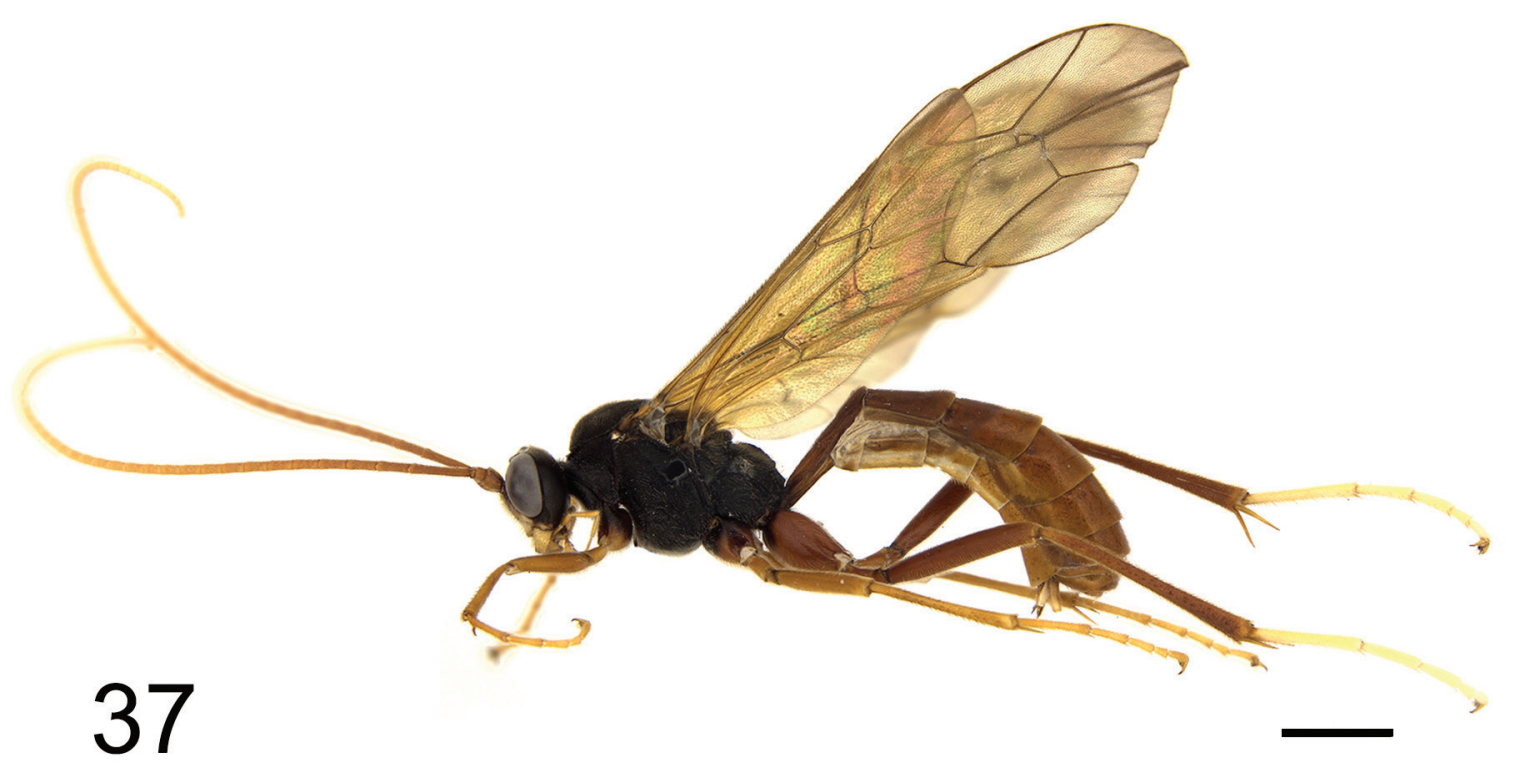

Fig. 37. Alexeter shakojiensis Uchida, 1930, q (GSFGPM), habitus, lateral view. Scale bar: 2 mm. 
Species of Alexeter are mainly found in the Palaearctic, Nearctic and Neotropical Regions (Yu et al. 2016), only one is also found in the Oriental Region (Luo et al. 2019; Sun et al. 2019; Sheng et al. 2020). Here, three new species are found in the Oriental Region, increasing the abundance of Alexeter in this fauna.

The distribution range of Alexeter in China goes from Jilin in the north to Guizhou in the south, and from Jiangxi in the east to Xizang in the west, with many areas still lacking proper collection. Future collections are needed to reveal the true diversity of the genus in China.

\section{Acknowledgements}

We are extremely grateful to Dr Gavin R. Broad (NHMUK) and an anonymous reviewer who provided detailed and useful reviews on this manuscript. The authors also thank Drs Gavin R. Broad (NHMUK), Masahiro Ohara (SEHU), Stefan Schmidt and Olga Schmidt (ZSM) for their help while the second author was working in their respective collections, and Kyohei Watanabe (KPMNH) for taking some photos of types of Alexeter Förster, 1869 from Japan. We would like to thank Prof. Mao-Ling Sheng (GSFGPM) who provided valuable suggestions that improved the quality of the manuscript. This research was supported by the National Natural Science Foundation of China (NSFC, no. 31501887, no. 31110103062) and by a key project of Science-technology basic condition platform from The Ministry of Science and Technology of the People's Republic of China (Grant no. 2005DKA21402).

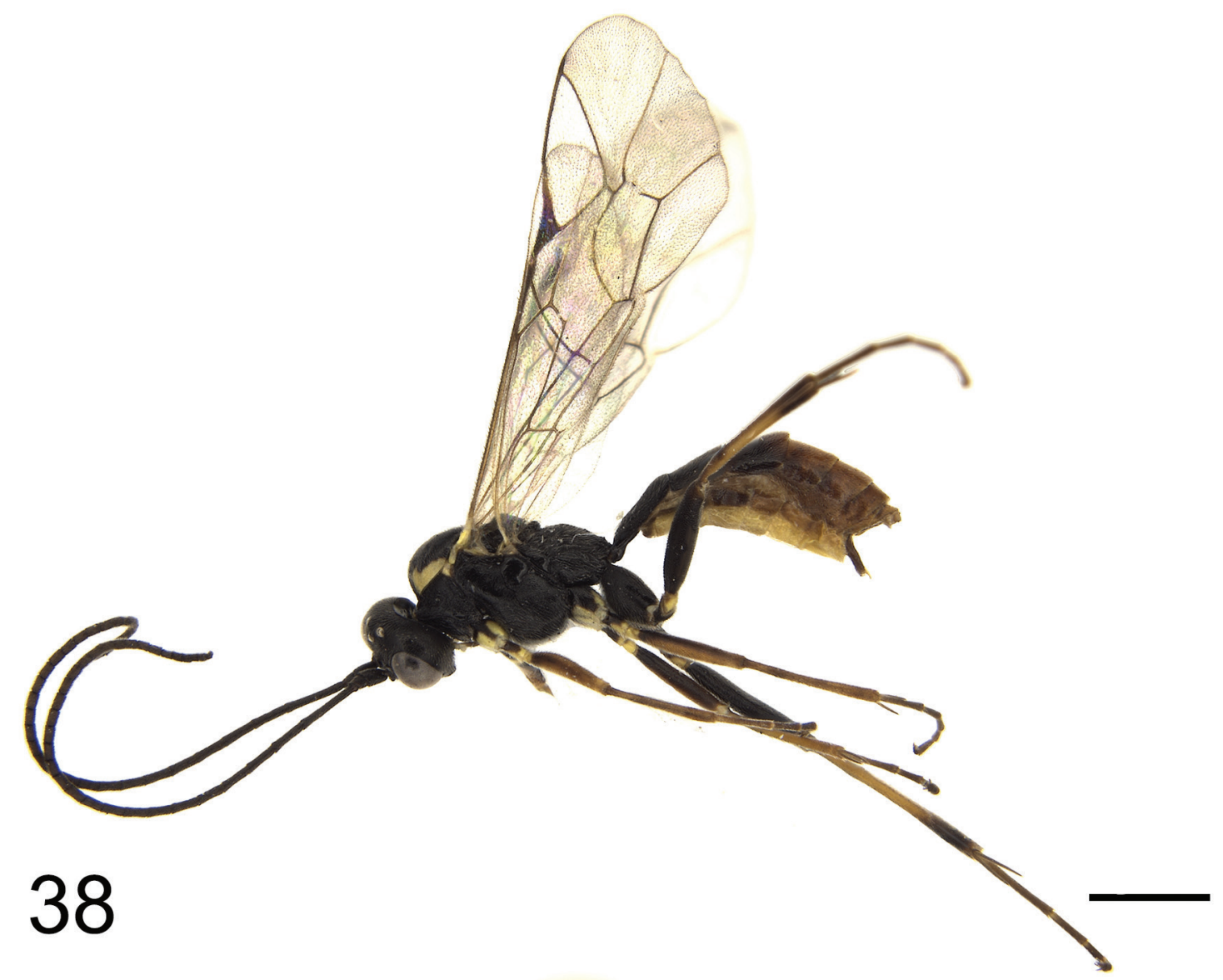

Fig. 38. Alexeter zangicus Sheng, Sun \& Li, 2020, holotype, $q$ (GSFGPM), habitus, lateral view. Scale bar: $1 \mathrm{~mm}$. 


\section{References}

Aubert J.F. 1998. Huitième supplément aux ichneumonidés, Scolobatinae, principalement du Musée de Saint-Pétersbourg (1). Bulletin de la Société entomologique de Mulhouse 1998: 17-25.

Aubert J.F. 2000. The West Palaearctic ichneumonids and their hosts. 3. Scolobatinae (=Ctenopelmatinae) and supplements to preceding volumes. Litterae Zoologicae 5: 1-310.

Broad G.R., Shaw M.R. \& Fitton M.G. 2018. Ichneumonid Wasps (Hymenoptera: Ichneumonidae): their Classification and Biology. Handbooks for the Identification of British Insects 7, Royal Entomological Society, St Albans.

Constantineanu M.I. \& Istrate G.I. 1973. Contributi la cunoasterea Ichneumonidelor parazite i daunatorii molidului (Picea excelsa Link) din judetul Suceava. Studii si Comunicari Stiintele Naturii. Muzeul Judetean Suceava 3: 289-307.

Förster A. 1869. Synopsis der Familien und Gattungen der Ichneumonen. Verhandlungen des Naturhistorischen Vereins der Preußischen Rheinlande und Westfalens 25 (1868): 135-221.

Gauld I.D., Wahl D., Bradshaw K., Hanson P. \& Ward S. 1997. The Ichneumonidae of Costa Rica, 2. Introduction and keys to species of the smaller subfamilies, Anomaloninae, Ctenopelmatinae, Diplazontinae, Lycorininae, Phrudinae, Tryphoninae (excluding Netelia) and Xoridinae, with an appendices on the Rhyssinae. Memoirs of the American Entomological Institute 57, The American Entomological Institute, Ann Arbor.

Heinrich G.H. 1949. Ichneumoniden des Berchtesgadener Gebietes. (Hym.). Mitteilungen der Münchner Entomologischen Gesellschaft 35-39: 1-101.

Heinrich G.H. 1953. Ichneumoniden der Steiermark (Hym.). Bonner Zoologische Beiträge 4: 147-185.

Hinz R. 1961. Über Blattwespenparasiten (Hym. und Dipt.). Mitteilungen der Schweizerischen Entomologischen Gesellschaft 34: 1-29.

Hinz R. 1996. Zur Systematik einiger Ctenopelmatinae (Hymenoptera, Ichneumonidae). Nachrichtenblatt der Bayerischen Entomologen 45 (3-4): 75-78.

Holmgren A.E. 1857. Försök till uppställning och beskrifning af de i sverige funna Tryphonider (Monographia Tryphonidum Sueciae). Kongliga Svenska Vetenskapsakademiens Handlingar N.F.1 (1) (1855): 93-246.

Li T., Sheng M.-L., Sun S.-P., Chen G.-F. \& Guo Z.-H. 2012. Effect of the trap color on the capture of ichneumonids wasps (Hymenoptera). Revista Colombiana de Entomología 38 (2): 338-342. Available from http://ref.scielo.org/v2qzh3. [accessed 12 Jan. 2021]

Luo X.-M., Sheng M.-F. \& Ding D.-S. 2019. A new Chinese record of Alexeter Förster (Hymenoptera, Ichneumonidae). South China Forestry Science 47 (1): 42-44.

Meyer N.F. 1936. Parasitic Hymenoptera of the Family Ichneumonidae of the USSR and Adjacent Countries. Part V. Opredeliteli po faune SSSR 21 (5), Academy of Sciences of USSR, Leningrad. [In Russian]

Müller O.F. 1776. Zoologiae Danicae prodromus, seu animalium Daniae et Norvegiae indigenarum characteres, nomina et synomyma imprimis popularium. Hafniae 151-160.

https://doi.org/10.5962/bhl.title.63795

Perkins J.F. 1962. On the type species of Förster's genera (Hymenoptera: Ichneumonidae). Bulletin of the British Museum (Natural History) (Entomology) 11: 385-483.

https://www.biodiversitylibrary.org/page/2260451 
Šedivý J. 1971. Ergebnisse der mongolisch-tschechoslowakischen entomologisch-botanischen Expeditionen in der Mongolei: 24. Hymenoptera, Ichneumonidae. Acta Faunistica Entomologica Musei Nationalis Pragae 14 (160): 73-91.

Sheng M.-L., Sun S.-P. \& Li T. 2020. Ichneumonids (Hymenoptera: Ichneumonidae) parasitizing sawflies in China. Science Press, Beijing. [In Chinese, with English summary]

Sun S.-P., Wang T., Sheng M.-L. \& Zong S.-X. 2019. A new species and new records of the genus Alexeter Förster (Hymenoptera, Ichneumonidae, Ctenopelmatinae) from Beijing with a key to Chinese species. ZooKeys 858: 77-89. https://doi.org/10.3897/zookeys.858.35012

Townes H.K. 1970. The Genera of Ichneumonidae, Part 3. Memoirs of the American Entomological Institute 13, The American Entomological Institute, Ann Arbor.

Uchida T. 1930. Vierter Beitrag zur Ichneumoniden-Fauna Japans. Journal of the Faculty of Agriculture, Hokkaido University 25: 243-298.

Uchida T. 1952. Einige neue oder wenig bekannte Ichneumonidenarten aus Japan. Insecta Matsumurana 18 (1-2): 18-24.

Viereck H.L. 1914. Type species of the genera of ichneumon flies. United States National Museum Bulletin 83: 1-186. https://doi.org/10.5479/si.03629236.83.1

Yu D.S., van Achterberg C. \& Horstmann K. 2016. Taxapad 2016, Ichneumonoidea 2015. Database on flash-drive. Nepean, Ontario.

Manuscript received: 1 March 2021

Manuscript accepted: 18 November 2021

Published on: 26 January 2022

Topic editor: Nesrine Akkari

Desk editor: Fariza Sissi

Printed versions of all papers are also deposited in the libraries of the institutes that are members of the EJT consortium: Muséum national d'histoire naturelle, Paris, France; Meise Botanic Garden, Belgium; Royal Museum for Central Africa, Tervuren, Belgium; Royal Belgian Institute of Natural Sciences, Brussels, Belgium; Natural History Museum of Denmark, Copenhagen, Denmark; Naturalis Biodiversity Center, Leiden, the Netherlands; Museo Nacional de Ciencias Naturales-CSIC, Madrid, Spain; Real Jardín Botánico de Madrid CSIC, Spain; Zoological Research Museum Alexander Koenig, Bonn, Germany; National Museum, Prague, Czech Republic. 